\title{
Race Research and the Ethics of Belief
}

\author{
Jonathan Anomaly
}

Received: 25 July 2016/Accepted: 21 October 2016/Published online: 15 March 2017

(C) Journal of Bioethical Inquiry Pty Ltd. 2017

\begin{abstract}
On most accounts, beliefs are supposed to fit the world rather than change it. But believing can have social consequences, since the beliefs we form underwrite our actions and impact our character. Because our beliefs affect how we live our lives and how we treat other people, it is surprising how little attention is usually given to the moral status of believing apart from its epistemic justification. In what follows, I develop a version of the harm principle that applies to beliefs as well as actions. In doing so, I challenge the often exaggerated distinction between forming beliefs and acting on them. ${ }^{1}$ After developing this view, I consider what it might imply about controversial research the goal of which is to yield true beliefs but the outcome of which might include negative social consequences. In particular, I focus on the implications of research into biological differences between racial groups.
\end{abstract}

Keywords Ethics of Belief - Heuristics and biases . Race $\cdot$ Racial differences

\footnotetext{
${ }^{1}$ According to William Clifford, "No real belief, however trifling and fragmentary it may seem, is ever truly insignificant ... gradually it lays a stealthy train in our inmost thoughts, which may someday explode into overt action, and leave its stamp upon our character forever" $(1877,292)$.
}

J. Anomaly $(\bowtie)$

Duke University, 140 Science Drive, 208 Gross Hall, Box 90204, Durham, NC 27708, USA

e-mail: jonathan.anomaly@duke.edu

\section{What's at Stake in the Ethics of Belief}

Imperfect knowledge is a fact of life for creatures who have limited time and scarce information and whose interest in forming true beliefs is shaped by our practical goals. Among our many goals is to acquire true beliefs. Sometimes we seek truth for the intrinsic satisfaction of understanding how the world works. ${ }^{2}$ But often we seek true beliefs only as a means of satisfying more mundane desires, such as finding our way around the New York subway system or figuring out which airline will get us to Hawaii at the lowest price. Since we have goals other than increasing our understanding of the world, we constantly face hard choices about the kind and quantity of information to gather, how long we should spend sifting through it, and the practical use to which we might put it.

Among our non-epistemic goals are that our particular desires are satisfied and that our life goes as well as possible. Sometimes forming true or justified beliefs can frustrate these goals, as when your belief that there is no God or that you have incurable cancer frustrates your desire to live forever. If our practical goals have at least some normative authority, we sometimes have good reasons to ignore evidence that would be salient if we were only concerned with forming true beliefs, and in

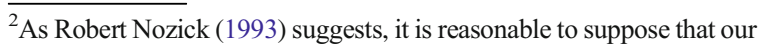
ancestors' interest in true beliefs was originally an instrumental one - it was selected for because it helped us survive and reproduce. But in a world with less scarcity, more leisure, and a longer life expectancy, many of us have a greater capacity to form accurate beliefs about the world and a greater desire to do so.
} 
some cases we may have reasons to (try to) form false beliefs. For example, if your acceptance of the fact that you have metastatic cancer makes it difficult for you to motivate yourself to get up in the morning, you may have reason-if it is possible - to avoid consuming detailed information about your grim prognosis, and you might try to form the belief that, against all odds, you are likely to overcome it. This may make your final days more pleasant and may help you satisfy other goals in the process. Of course, beliefs are not fully voluntary, so we cannot change them like hats or shoes. But we can influence our beliefs by either ignoring or seeking out evidence that bears on a hypothesis, or by altering our epistemic environment in ways that make such evidence more or less likely to emerge in our daily interactions. ${ }^{3}$

The potential conflict between forming true beliefs and increasing our welfare is made clear when we distinguish two kinds of rationality, each with its own aim. Epistemic rationality aims at truth, while instrumental rationality aims at satisfying our desires, whatever their content. Robert Nozick $(1993,70)$ contrasts two statements that bring into stark relief the difference between instrumental and epistemic rationality:

$\mathrm{p}$ is the rational thing to believe

Believing $\mathrm{p}$ is the rational thing to do

Suppose "p" is the proposition that "my client is guilty," and it is held by a defence lawyer. The belief may be justifiable in light of the evidence and ultimately true. But if a defence lawyer allows herself to form this belief, especially if her client is accused of an especially gruesome crime, she might exert less effort defending her client in court. Similarly, if "p" is "my basketball team will lose," and it is believed by most members of the team, they may not try as hard to win the game. Whether I ought to believe that my client is guilty or my basketball team will lose depends in part on what the point of this belief is - to form a justified belief about the world, given my current evidence, or to accomplish the goal of defending my client or winning a game.

\footnotetext{
${ }^{3}$ There are limits to what kinds of beliefs you can try to shed or form for purely instrumental reasons. For example, if your acceptance of causal determinism saps your energy and makes it difficult to care about goals you once found important, you may have good reason to try to believe causal determinism is false or that it is compatible with free will (though if causal determinism and free will are, in fact, in conflict, you cannot have normative reasons to believe otherwise, since all normative reasons collapse in a world in which our beliefs are outside of our control).
}

These examples illustrate how beliefs can become self-fulfilling (or self-undermining) prophecies. They can do this partly by functioning as placebos that alter our confidence that a goal is achievable or worth achieving. More importantly, these examples show that our epistemic and practical goals can come apart: our beliefs about what the world is like can determine whether our desires are satisfied and more generally how well our lives go.

In addition to our beliefs affecting our welfare by altering our actions or character, they can also influence other people's welfare. Obvious examples include religious beliefs that command followers to tolerate infidels or execute them. But more common cases are beliefs about who we should vote for or what kind of clothing is appropriate at a wedding or a funeral. In these cases, each person's beliefs inform their actions and have a small impact on how other people vote or how they dress. But the aggregate impact of each of these beliefs (to the extent that people act on their beliefs) shapes entire cultures, determines who is elected, and affects the availability and price of different goods.

Our beliefs can affect ourselves and others in many ways, but I will focus on beliefs that have some advantage for the individual but which may reduce the welfare of others. Harm can occur either because the belief causes believers to act in ways that harm others directly or indirectly (e.g. religious fanatics who kill infidels or encourage others to do so) or contributes to an epistemic environment in which people are worse off from the standpoint of truth (e.g. influential celebrities who promote astrology as a way of organizing our lives). The pursuit of truth should not always trump our practical concerns, but there is at least some reason to be concerned when people spread beliefs that contribute to an environment that impairs other people's ability to form true beliefs or carry out their plans.

\section{The Harm Principle}

According to the harm principle developed by John Stuart Mill, "the only purpose for which power can be rightfully exercised over any member of a civilized community, against his will, is to prevent harm to others" (1869). Mill deploys the harm principle as a normative benchmark for determining when it is appropriate to use state power to curtail the freedom of people to speak and act as they please. But my aim is different 
than Mill's: I want to use a version of the harm principle to help us draw a principled (but vague) line between when it is, and is not, morally permissible to form and act on beliefs that are likely to affect other people, including how they think and behave. I'll argue that it is morally defensible to hold socially consequential beliefs for which there is imperfect evidence only if doing so is unlikely to impose significant, uncompensated harm on other people.

The "imperfect evidence" proviso is crucial for two reasons: first, if we know something to be true, it is arguably impossible to resist believing the proposition; second, it seems counterproductive from a social standpoint to continually try to suppress socially consequential beliefs that are known to be true. Even when evidence is imperfect, it is worth recognizing that moral and epistemic standards for belief can come into conflict. There may be good epistemic reasons for holding a belief that has bad moral consequences and good moral reasons for holding a belief that has bad epistemic consequences. $^{4}$

Some have argued that the harm principle is hopeless as a normative standard because there are many different kinds of harms, because it is arbitrary where we establish the baseline relative to which harm occurs, or because the concept of harm is itself so ambiguous and context-dependent that it is useless in moral thinking (Holtug 2002; Bradley 2012). But I think these are benefits rather than costs of value-laden terms like "harm," "liberty," "rights," and "welfare." The ambiguity of "harm" allows us to make distinctions between kinds of harms, including psychological harm, physical harm, and environmental harm, and to argue about which kinds of harm matter in particular cases. Global scepticism about using "harm" as a moral standard is also unwarranted because any term we replace it with, such as "badness," is also both vague and ambiguous. Like "harm," terms like "badness" can be given a subjective or objective reading and can be used in indefinitely many ways depending on the context. But this is not an objection to framing moral debates around such terms. Quite the opposite.

Consider how strange it would be if Thomas Jefferson had specified with precision in the Declaration of Independence what he meant when he invoked a right to "life, liberty, and the pursuit of happiness." Would

\footnotetext{
${ }^{4}$ And since "ought-implies-can" only one of these reasons can be
} decisive.
Americans be better off if he had listed a precise set of liberties or specified a particular view of happiness? Deliberately vague language can also be helpful in delineating the basic form rights take in a constitutional democracy, as in the Bill of Rights of the U.S. Constitution. For example, the First Amendment to the U.S. Constitution protects free speech ("Congress shall make no law ... abridging the freedom of speech ...") but enables citizens and judges to work out a more precise extension of the term as social norms and circumstances change. For example, some argue that donating to organizations that fund political advertising is a form of speech, while others describe donations as an attempt to buy electoral outcomes. Similar considerations apply to "harm."

Any plausible version of the harm principle should also acknowledge that even when our actions affect others in a negative way, allowing harmful actions can have compensating benefits over the long run. For example, when Charles Darwin formulated the theory of evolution by natural selection, he knew that publishing his theory would shatter many people's religious faith by undermining their teleological worldview. Darwin confided to his friend Joseph Hooker that "it is like confessing a murder" to say that species are not immutable and that, contrary to other evolutionary theories of the time, organisms do not "progress" toward better or more perfect forms.

While propagating the theory of evolution by natural (and sexual) selection undoubtedly caused many to lose their faith, which brought about some short-run psychological harm, over the long run Darwin's theory contributed to our ability to understand the world and our place in it and to medical advances that help everyone.

\section{Ignorance, Irrationality, and Harm}

Believing is often a socially significant act. To return to a previous example, if we intend to cast a vote in a national election or discuss politics with other people whose vote we have the power to influence, forming beliefs about the issues and candidates has a marginal impact on the outcome of the election. Since all citizens (and some non-citizens) incur the legislative consequences of an election, we seem to bear responsibility for how we go about forming our political beliefs.

The problem is that effort exerted to gather relevant political information in an unbiased way is costly in the 
psychological sense that revising our beliefs and admitting we may be wrong makes us uncomfortable. Moreover, time spent forming beliefs about politics is time not spent on other activities that we enjoy or that we have good reasons to engage in. To the extent that good governance is a shared goal and is best achieved through democratic elections, the benefits of good faith efforts to consume unbiased information for the purposes of voting are shared by all voters, but the costs are internalized by each voter.

Economists have long argued that most people are rationally ignorant about politics because they lack the ability to influence political outcomes with their individual vote (Downs 1957). In market settings it is instrumentally rational for each of us to gather information about the products we wish to purchase, since we know we'll have to live with the consequences of our choices, and we are reasonably sure that when we hand over the cash we will obtain the product we pay for. The beliefs we form in the marketplace will tend to be epistemically justified because we need reliable beliefs about the products we consume for our desires to be satisfied. ${ }^{5}$ But in politics we know that we have almost no chance of influencing an electoral outcome by voting, and this has implications for how much information we collect and what we do with it.

Notice that markets, too, promote a certain kind ignorance - one that arguably makes all of us better off. As Friedrich Hayek argues (1945), there are net social benefits when each of us specializes in a particular set of tasks, gathers local knowledge about how to satisfy our customer's desires, and then acts on that knowledge. If I become a mechanic and you become a plumber, and we trade services, we're both better off for the exchange. And the more this happens - the more fine-grained the division of labour becomes - the better off we become (Smith 1776, Book I). But we also tend to become more ignorant about the details of how the products we buy are made or the scientific principles that go into creating new products (Smith 1776, Book $\mathrm{V})$. In this sense, ignorance about how most things work is both rational and socially beneficial because it allows

\footnotetext{
${ }^{5}$ This is not to say that all of our desires, especially those induced by propaganda or influenced by fashion and other social fads, are worth attempting to satisfy, only that once we have goals in the marketplace, we will tend to gather reasonably reliable information about how to satisfy them since we bear the costs and benefits of our choices. This is not true in situations of interdependence, in which what we choose has little if any causal influence over the outcome we end up with.
}

each of us to spend more time doing what we're good at and selling the surplus to others. We don't need to know how to build cars, create vaccines, or construct skyscrapers in order to enjoy the benefits of all of these things. In markets, then, we are rationally ignorant about most of what goes on around us apart from our own occupation and the price and quality of the objects we buy.

In politics, rational ignorance can be dangerous, especially if ignorant citizens cast votes. While economists have focused on rational ignorance, many philosophers and political psychologists have argued that citizens in democratic countries are not only ignorant but positively irrational (in the epistemic sense) because they are inclined to consume information in a biased way (Caplan 2001; Huemer 2015). Most voters engage in motivated reasoning and are especially susceptible to confirmation bias in the sources of information they seek out (Haidt 2012), in part because they understand the insignificance of forming beliefs about a realm that they cannot reasonably hope to affect. Thus, democratic citizens often form beliefs and vote in ways that express their identity or symbolically affirm their values, rather than carefully evaluate evidence about the efficacy of specific policies advanced by political parties or candidates (Brennan and Lomasky 1993; Somin 2013).

If rationally ignorant and epistemically irrational voters impose net harms on other people, and if refraining from acting on their beliefs is cheap, they arguably have a moral obligation not to vote on the basis of political views for which they lack justification (Brennan 2009). By extension, they seem to have a moral obligation not to form strong beliefs in the political realm if they will predictably act on them by getting in political arguments or voting.

These examples illustrate how socially consequential some of our beliefs are, especially in situations of interdependence, when each of us faces similar incentives and all of us share the consequences of one another's choices. I now want to turn to the moral status of beliefs about racial differences because these beliefs have profound effects on how we think of other people and how we treat them. Historically, such beliefs have been used to justify warfare, slavery, genocide, legally sanctioned discrimination, and destructive social norms. Less dramatically, beliefs about group differences can lead to implicit bias and subtle forms of racism. If research suggests that there are genetically mediated differences between racial groups, would our awareness of them 
lead us to treat one another less fairly? And in the absence of conclusive evidence, should we (try to) refrain from forming beliefs about different groups, or should we openly embrace what we think the evidence suggests?

\section{Race Research}

The power to uncover the genetic and evolutionary roots of group differences in psychological traits is ... a prospect that we are, intellectually and emotionally, very poorly equipped to confront.

$\sim$ Steven Pinker, "Groups and Genes"

In the last few years, a handful of authors have made the provocative claim that there are small but significant genetic differences between different groups (or "races") of people and that these differences can explain some observable differences in behaviour.

Not all academics who maintain that races are merely social constructions deny that there are biological differences between groups of people. For example, Sally Haslanger (2000) argues that we might divide people up into lactose tolerant and lactose intolerant, light-skinned and dark-skinned, or tall and short. All of these properties have biological (often genetic) causes, and they are differentially distributed across the human population. Haslanger rightly argues that we need good reasons to accept any particular classification and that if the only point of classifying people is to subordinate or oppress them, we should reject that classification. But many researchers do think there are good reasons to make racial and ethnic classifications in the same way that there are good reasons to distinguish tables and chairs even if kinds of furniture are ultimately just bundles of atoms with different properties. In this sense, most things around us are socially constructed, but that doesn't mean that all socially constructed categories are equally useful in helping us navigate the world.

Among those who think it is useful to categorize people into different races or ethnicities, there is some controversy about how to do so. This is because most genetic differences, or differences in allele frequencies, occur within as well as between groups. But some argue that it helps to have a term like "race" to distinguish average genetic differences between groups, especially when genetic differences are linked to statistically significant behavioural outcomes. ${ }^{6}$ I do not take a position on how best to divide human groups. My concern is only to discuss the implications of beliefs people form about group differences when these beliefs are sensitive to scientific discovery about the genetic basis of group differences.

The claim that there are average differences between groups in stature, hair texture, skin colour, and other physical traits is often accepted even by those who think racial groupings are social constructions. But claims that genes play a role in producing differences in cognitive traits that bring success in the modern world - such as intelligence and impulse control—are often greeted with embarrassed silence or harsh denunciation, independent of their scientific merit (Haidt 2009).

Steven Pinker points out that,

$\ldots$ in recent decades, the standard response to claims of genetic differences [in intelligence] has been to deny the existence of intelligence, to deny the existence of races and other genetic groupings, and to subject proponents to vilification, censorship, and at times physical intimidation. (2006a, I29)

Jonathan Haidt recounts that after the publication of E.O. Wilson's Sociobiology, which proposed among other things that gene-culture co-evolution might explain some behavioural differences between groups, Wilson "was harassed and excoriated, in print and in public. He was called a fascist, which justified (for some) the charge that he was a racist, which justified (for some) the attempt to stop him from speaking in public" $(2012,38)$. Similarly, as the author of a recent book on race and evolution observes, "the idea that human populations are genetically different from one another has been actively ignored by academics and policy makers for fear that such inquiry might promote racism" (Wade 2014, 249).

It appears that many people oppose entertaining the possibility that small genetic differences might help explain why, for example, West African athletes tend to dominate sprinting events or East Asians and

\footnotetext{
${ }^{6}$ It is increasingly common to use Single Nucleotide Polymorphisms (SNPs) to infer the genetic distance between groups (Rosenberg et al 2002). Some scholars use this technique as a way of picking out groups that correspond to our common conception of "race" even when SNPs involve non-coding DNA (Spencer 2014). Others use "race" to refer to genetically-mediated phenotypic traits that we find salient for social or scientific purposes (Mayr 2002; Kitcher 2007).
} 
Ashkenazi Jews tend to excel in mathematics, not because these hypotheses are demonstrably false but because believing them (or propagating these beliefs) would lead to bad social consequences (Hunt 1999; Pinker 2002). In other words, it looks like many people's implicit commitment to some version of the harm principle explains why they so vehemently oppose even the thought that socially significant biological differences exist between groups.

There are several ways in which forming beliefs about group differences might lead to social harm. However, there are also benefits associated with grounding our beliefs in the best evidence available and pursuing that evidence even when there are short-term harms associated with it. So, this is a good test case for applying the harm principle developed above. In what follows, I compare the potential harms and benefits associated with believing that there are biological differences between groups of people - differences that correspond, to some extent, with our folk concepts of race.

Harms

Bias

We all form subconscious judgments about the strangers we encounter by associating them with particular groups. For example, attractive people with symmetrical features are widely considered more competent than unattractive people, obese people are often thought to be lazy, and immigrants with unfamiliar accents are thought to be less trustworthy than native born citizens (Haidt 2012, 68). Researchers tend to focus on negative implicit biases that are at odds with our explicit values or with what we believe to be true. But not all biases are irrational, and not all stereotypes are inaccurate.

Some scholars argue that in certain domains stereotypes are remarkably accurate, but that researchers are afraid to acknowledge this because they are inclined to believe that "if stereotypes are associated with social wrongs, they must be factually wrong" (Jussim et al. $2015,34)$. This is similar to the fact that people who oppose torture or capital punishment on moral grounds are more likely to believe that they are not effective punishments, which is a separate issue that should not be influenced by our moral judgements.

Other scholars (Cosmides and Tooby 1994; Gigerenzer and Brighton 2009) argue that many of our biases and heuristics can be explained as adaptations that in some cases function better than conscious reasoning for the kinds of problems they evolved to solve. Our distrust of foreigners may be an example of a bias that was once adaptive but now less useful. Being more apprehensive of men than women may be a bias that is still useful. The difference between a "heuristic" and a "bias" is not always clear, but in general heuristics are principles or devices we use, often unconsciously, to make choices, while biases are attitudes or beliefs that incline us to view an action, person, or group favourably or unfavourably. The basis of both is often accumulated personal experience and inductive generalization from specific cases to general types. The heuristic that leads us to fear men more than women may be individually rational and socially beneficial, since ignoring group differences would likely lead people, especially women, to be less cautious around men who want to harm them.

Still, if evidence emerges showing that there are genetic differences between groups in the distribution of traits that we care about, it is likely that some people who believe this evidence will be more likely to use it to justify unjust prejudice. More specifically, some people might be more likely to believe stereotypes that lead them to treat individuals as mere members of a group.

We all use heuristics to guide our everyday choices, and among these heuristics are stereotypes that may be instrumentally useful but collectively harmful. When we choose who will be on our basketball or football team in a pickup game and the pool of available participants is racially diverse, it is common to choose people of some racial groups rather than others in the absence of any other information. Rational discrimination in this case occurs either because we justifiably believe members of some groups tend to play the game more or because we think they're more likely to have biological advantages that make them better players. The aggregate effect of discrimination that is individually rational may be to reinforce negative stereotypes. Stereotypes in sports are not especially harmful. But when we stereotype in the classroom and in the workplace, it may produce results that are unfair for particular members of a group and for all members of a group with whom we associate certain traits.

Résumé experiments illustrate why this is true. Some studies suggest that names on résumés that are more likely to be associated with black Americans are less likely to be given consideration relative to other racial groups (Bertrand and Mullainathan 2004). Political bias, as gauged by omitting candidates' names on resumes but including indicators of political affiliation, may be 
even more prevalent than racial bias (Iyengar and Westwood 2015). If priming people with indicators of group membership can lead to discrimination (whether justified or not) in simple experiments like this, it is likely that these attitudes are commonly held. Thus, we might fear that if evidence indicates that different racial groups have average differences in aptitudes or propensities, these biases might be exacerbated.

It is also, of course, possible that priming people with the knowledge that their group is, on average, not very good at a certain task may lead them to exert less effort or to treat certain options as not viable or salient. The magnitude and existence of "stereotype threat" (as this has been called) has not been conclusively demonstrated and has been difficult to replicate (Jussim 2015), but it seems like a real possibility: while some people welcome the challenge and try to overcome negative stereotypes, others might think it's not worth trying to do something that, on average, members of their group do not excel at.

\section{Oppression}

Much more worrisome than bias, perhaps, is the fact that beliefs about group differences may lead some to consider one group "superior" to another. Beliefs about the superiority of one race over another might lead people (as it has in the past) to use government power to deprive some people of legal rights or social entitlements in virtue of their membership in a group. Historical cases of race and gender-based oppression are so numerous that there is no point in providing examples.

Given how potentially damaging these harms are, and how complex and imperfect the current biological evidence to support racial differences is, should we allow ourselves to believe in them? What if evidence emerges to support certain prevailing prejudices that have already been used to justify unfair discrimination? Should we attempt to prevent widespread belief in group differences by suppressing research or ignoring its conclusions if believing them would undermine our ability to treat other people fairly?

In the absence of compensating benefits, the harm principle would seem to condemn believing in racial differences, and this would suggest a moral argument for spurning research into racial differences (Kitcher 2003, 105). But there are many reasons to think that, in spite of these risks, refusing to accept evidence for conclusions we'd prefer not to believe carries its own risks - including the forgone opportunity to know the truth, the ability to make rational generalizations, and the ability to use this information for socially beneficial purposes. Stigmatizing such research may also lead it to be done by cranks rather than scientists.

\section{Benefits}

\section{Intrinsic Benefits: Truth and Explanatory Power}

Steven Pinker rhetorically asks, "Don't the demands of rationality always compel us to seek the complete truth? Not necessarily. Rational agents often choose to be ignorant." Still, Pinker argues, "If an idea is true, we had better accommodate our moral sensibilities to it, since no good can come from sanctifying a delusion" (2006b). Similarly, James Flynn (famous for discovering the "Flynn effect") concludes that,

$\ldots$ if Jensen's thesis [that there are racial differences in intelligence] is correct, the path to social justice will be more difficult. However, if he is correct, he will have done us the favor of forcing us to face a facet of reality many are reluctant to accept. Would anyone who holds humane ideals prefer to pursue them in a fantasy world than in the real world. $(1999,12)$

The answer is only partly convincing. Many scientists and academics put a high value on truth for its own sake, at least in domains they care about. But sometimes the pursuit of truth makes our lives go worse rather than better, and some illusions may be worth preserving either because they make our individual lives go better or because they might (in principle) lead to good social consequences. For example, if athletes who are especially confident about their abilities tend to perform better, or cancer patients who are more optimistic about their prognosis than the evidence justifies tend to live happier lives, this may be a reason to allow themselves to believe false propositions. At some point, of course, misplaced confidence can undermine our ability to achieve our goals by making us complacent or delusional. More to the point, if we allow ourselves to believe a proposition that is contrary to the available evidence, we may end up acting in ways that harm other people as well as ourselves - in the case of sports, by letting our team down, and in the case of cancer, by failing to draft a legally binding will. These mundane examples show that it is sometimes worth clinging to epistemically dubious 
beliefs that make our lives go better as long as doing so doesn't significantly harm other people. The problem in making this assessment for socially consequential cases is that our knowledge of the relevant trade-offs and the probability of harm is limited, even if we would be willing to forgo some truth if we knew with certainty that the social gains from doing so were large.

One thing justified beliefs about racial differences might help us do is to explain - and also undermine rather than justify - prejudice against particular groups of people. For example, many have noticed the astonishing achievements of Ashkenazi Jews over the last few centuries, and some have attributed a largely biological cause (Cochran, Hardy, and Harpending 2005). Informal evidence includes the relative success of Ashkenazi Jews in many different countries, even in the presence of social and legal discrimination. More rigorous evidence comes from the percentage of Nobel prizes and other scientific accolades Ashkenazi Jews were awarded in the twentieth century and from the heritability of IQ scores (Ashkenazi IQ is the highest in the world, nearly a full standard deviation above the European average). IQ gaps persist between Ashkenazi Jews (from Northern Europe) and Sephardic Jews (from Southern Europe) in every country in which they are currently found, including Israel and the United States. An increasingly common explanation for these differences is that Ashkenazi intelligence resulted from relatively recent natural selection, sexual selection, and gene-culture co-evolution, all of which can occur rapidly in relatively isolated populations with significant resource scarcity (Cochran and Harpending, 2009).

If all people begin as blank slates (or if all groups have an identical distribution of intelligence), it is hard to explain how groups like Ashkenazi Jews in Europe who have had less access to social benefits than their surrounding populations outperformed them in many of the most cognitively demanding occupations, including science and medicine. On the assumption that groups are identical, some of the more gullible citizens of Europe in the early twentieth century began to explain Jewish success as a product of theft, manipulation, and even supernatural deals with the devil. Accepting a partly genetic cause of Jewish success may help explain the obvious disparities between Jews and other groups who used their success as an excuse for persecution. Whether coming to accept this hypothesis would prevent persecution is hard to know, but it may satisfy our desire to explain why, in fact, Ashkenazi Jews have been singled out for their success rather than their failure.

Similarly, if West Africans (and their descendants around the world) have superior sprinting skills because of slight genetic advantages in the quantity or distribution of fast-twitch muscle mass, we should expect to see them disproportionately represented in sprinting events at the Olympic Games, as well as in basketball, football, and other sports that require these skills. Understanding this may help satisfy our curiosity about why members of some groups are more likely than others to excel at particular activities. As James Crow explains, "whenever a society singles out individuals who are outstanding or unusual in any way, the statistical contrast between means and extremes comes to the fore" $(2002,85)$.

For example, Crow argues, "Consider a quantitative trait that is distributed according to the normal, bellshaped curve. IQ can serve as an example. About one person in 750 has an IQ above 148. In a population with an average of about 108 rather than 100, hardly a noticeable difference, about 5 times as many will be in this high range. In a population averaging 8 points lower, there will be about 6 times fewer. A small difference of 8 points in the mean translates to several-fold differences in the extremes" (2002, p. 85). This fact, Crow believes, may help explain why East Asians and Ashkenazi Jews are disproportionately represented in American universities. Like sprinting skills, IQ reflects the interaction of genetic predispositions and environmental inputs. But when empirical regularities occur across different societies and diverse environments, there is at least some reason to believe biology plays a role. And knowing this fact may help us explain the world around us a little bit better.

Apart from an intrinsic desire to have true beliefsbeliefs that help us explain and predict events around us - we may also have reasons to believe in biological differences between groups (when the evidence justifies them) in spite of the risks because doing so will have social benefits. These include medical diagnosis and fighting rather than reinforcing unjust discrimination.

\section{Instrumental Benefits: Medical Diagnosis and Bias Recognition}

As the previous example suggests, harm can come not only from the presence of ideas, whether true or false, but from the absence of hypotheses that are 
not pursued because of an intellectually stifling climate. For example, many racists and conspiracy theorists continue to explain Jewish success by appealing to their moral depravity - the idea that theft, conspiracy, or even sorcery are the sources of Jewish success. When beliefs like these are widely shared, they are more likely to lead to anti-Semitic actions (like the pogroms in Russia) and policies (like the Nuremberg laws in Germany). Recognizing differences, then, may be socially beneficial if it gives a better explanation of the relative success of different groups in different domains.

A more pressing way in which research into racial differences, and a willingness to recognize them, can be socially beneficial is in medical diagnosis. It is increasingly common for physicians to use information about race to tailor the tests they recommend and the advice they give to patients. There is good evidence, for example, that Native American and Inuit people are especially susceptible to Type 2 diabetes, sub-Saharan Africans to hypertension and sickle cell anaemia, Ashkenazi Jews to breast cancer and Tay Sachs disease, and Europeans to cystic fibrosis and hemochromatosis. Some of these are purely genetic disease, while others are predispositions activated by environmental factors or chance. But even mere predispositions differentially affect populations, and in some cases the genes that cause them were selected for under conditions in which they conferred some benefit.

Eventually, it is likely that patients will have their entire genome sequenced, and their susceptibility to particular disorders or strengths will be able to be inferred more directly. But until then - until the time this technology improves, the price falls, and our understanding of genetics significantly increasespaying explicit attention to race for medical purposes can be quite useful (Crow 2002). This suggests that healthcare professionals and researchers should openly acknowledge at least some racial and ethnic differences but should not use them to disparage people (for moral reasons) or treat all members of a group as representing the average (for scientific reasons).

The fear that recognizing, or explicitly believing in, racial differences might bolster biases that we'd prefer not to act on is legitimate. But becoming conscious of our biases, especially those we think of as unjustifiable, may help us mitigate them. One reason economics, psychology, and philosophy are worth studying is that each subject teaches us ways in which we systematically make crucial mistakes. For example, economics teaches us that-contrary to the way we naturally tend to think-trade is not a zero-sum game but a game (or situation of interdependence) with increasing returns as trading networks expand. Understanding this helps us get a better grasp on the world and helps us become more responsible voters.

Similarly, most people are prone from an early age to stereotype and to treat people as if each of them embodies qualities of an average member of their group. Understanding this, and learning to sort out useful from harmful biases, may help us reduce unjust stereotyping and create a more tolerant and just society. Recognizing bias, and overcoming it, is a crucial function of moral learning and epistemic maturity.

A common response to proposals that there are biological differences between groups-including race and sex-is to dismiss them outright and to brand those who believe in such differences as racists and sexists. This is a serious mistake, not only because it can create the conditions for treating those who hold such beliefs unfairly but also because it tends to reinforce the assumption that a commitment to moral equality depends on biological identity. As Anthony Edwards argues, "it is a dangerous mistake to premise the moral equality of human beings on biological similarity because dissimilarity, once revealed, then becomes an argument for moral inequality" (2003, 801). If we agree that our commitment to equality does not depend on the biological identity of individuals or groups, research that uncovers these differences should not weaken our moral commitment. Understanding why people should be treated as individuals rather than as mere members of groups should ultimately increase social welfare by providing us with robust reasons to treat each other as moral equals (Singer 2011, chapter 2).

All of these considerations suggest that we should remove the social stigma that currently goes along with research into the genetic basis of group differences. If research is likely to be done anyway, it is better to have findings that can withstand scrutiny than to stay silent while crackpots generate dubious data that reinforces existing prejudice (Winegard et al 2017). In other words, just as some beliefs can cause harm when they are put into action, so too can the suppression of beliefs. 


\section{Conclusion}

Beliefs can be used as weapons, not only because they can lead us to act in repugnant ways but also because they affect our epistemic environment. I have argued that there are clear cases in which beliefs can lead to bad social consequences, especially in the political realm where each of us is indirectly affected by the beliefs of voters and policymakers. In cases like this, we often have obligations to refrain from forming strong beliefs or acting on them. I have also argued that there are cases in which the evidence is inconclusive but suggests a hypothesis that has the power to produce significant social harm, or benefits, depending on how we respond to it. Specifically, the hypothesis that biological differences exist between groups of human beings has the power to produce vast amounts of harm by reinforcing stereotypes and giving members of some groups an excuse to persecute others. But hypotheses that make us uncomfortable need not produce bad results. By leading us to reconsider the proper basis of our moral commitments and to actively consider the trade-offs between beneficial and harmful heuristics, beliefs about group differences need not produce social harm, as they have in the past, but may offer us the chance to increase the stock of beliefs that are both true and socially beneficial.

\section{References}

Bertrand, M., and S. Mullainathan. 2004. Are Emily and Greg more employable than Lakisha and Jamal? A field experiment on labor market discrimination. American Economic Review 94(4): 991-1013.

Bradley, B. 2012. Doing away with harm. Philosophy and Phenomenological Research 85(2): 390-412.

Brennan, J. 2009. Polluting the polls: When citizens should not vote. Australasian Journal of Philosophy 87(4): 535-549.

Brennan, G., and L. Lomasky. 1993. Democracy and decision. Cambridge University Press.

Caplan, B. 2001. Rational ignorance vs rational irrationality. Kyklos 54(1): 3-26.

Clifford, W. 1877 [1999]. The ethics of belief. In The ethics of belief and other essays, edited by T. Madigan, 70-96. Amherst, MA: Prometheus.

Cochran, G., J. Hardy, and H. Harpending, 2005. Natural history of Ashkenazi intelligence. Journal of Biosocial Science 38(5): 659-693.

Cochran, G., and H. Harpending. 2009. The 10,000 year explosion: How civilization accelerated human evolution. New York: Basic Books.
Cosmides, L., and J. Tooby. 1994. Better than rational: Evolutionary psychology and the invisible hand. American Economic Review 84(2): 327-332.

Crow, J. 2002. Unequal by nature: A geneticist's perspective on human differences. Daedalus 131(1): 81-88.

Downs, A. 1957. An economic theory of political action in a democracy. The Journal of Political Economy, 65(2): 135150 .

Edwards, A. 2003. Human genetic diversity: Lewontin's fallacy. BioEssays 25(8): 798-801.

Flynn, J. 1999. Searching for justice: The discovery of IQ gains over time. American Psychologist 54(1): 5-20.

Gigerenzer, G., and H. Brighton. 2009. Homo heuristicus: Why biased minds make better inferences. Topics in Cognitive Science 1(1): 107-143.

Haidt, J. 2009. Faster evolution means more ethnic differences. Edge.org. https://edge.org/response-detail/10376. Accessed February 8, 2017.

- 2012. The righteous mind: Why good people are divided by politics and religion. New York: Vintage Books.

Haslanger, S. 2000. Gender and race: What are they? What do we want them to be? Nous 34(1): 31-55.

Hayek, F. 1945. The use of knowledge in society. American Economic Review 35(4): 519-530.

Holtug, N. 2002. The harm principle. Ethical Theory and Moral Practice 5(4): 357-389.

Huemer, M. 2015. Why people are irrational about politics. In Philosophy, Politics, \& Economics, edited by J. Anomaly, G. Brennan, M.C. Munger, and G. Sayre-McCord, 456-467. Oxford: Oxford University Press.

Hunt, M. 1999. The new Know-Nothings. New Jersey: Transaction Publishers.

Iyengar, S., and S. Westwood. 2015. Fear and loathing across party lines: New evidence on group polarization. American Journal of Political Science. 59(3): 690-707.

Jussim, L., J. Crawford, S. Anglin, J. Chambers, S. Stevens, and F. Cohen. 2015. Stereotype accuracy: One of the largest and most replicable effects in all of social psychology. In Handbook of prejudice, stereotyping, and discrimination, 2nd ed, 31-63. London, U.K.: Taylor \& Francis.

Jussim, L. 2015. Is stereotype threat overcooked, overstated, and oversold? Heterodox Academy. December 30. http:/heterodoxacademy.org/2015/12/30/is-stereotypethreat-overcooked-overstated-and-oversold/. Accessed February 08, 2017.

Kitcher, P. 2003. Science, truth, and democracy. Oxford: Oxford University Press.

- 2007. Does 'race' have a future? Philosophy \& Public Affairs 25(4): 293-317.

Mayr, E. 2002. The biology of race and the concept of equality. Daedalus 131(1): 89-94.

Mill, J.S. 1869. On liberty. http://www.econlib. org/library/Mill/mlLbty1.html

Nozick, R. 1993. The nature of rationality. Princeton: Princeton University Press.

Pinker, S. 2002. The blank slate: The modern denial of human nature. Viking Press.

- 2006a. Groups and genes: Lessons of the Ashkenazim. The New Republic, June 26. http://www.newrepublic. com/article/77727/groups-and-genes. Accessed February 8, 2017. 
2006b. In defense of dangerous ideas. Edge.org, December 31, 2006. https://edge.org/conversation/prefaceto-dangerous-ideas. Accessed February 8, 2017.

Rosenberg, N. 2002. Genetic structure of human populations. Science 298(20): 2381-2385.

Singer, P. 2011. Practical ethics, 3rd ed. Cambridge: Cambridge University Press.

Smith, A. 1776. An inquiry into the nature and causes of the wealth of nations. Econlib.org/library/smithsmWN.html
Somin, I. 2013. Democracy and political ignorance. Palo Alto, C.A.: Stanford University Press.

Spencer, Q. 2014. A radical solution to the race problem. Philosophy of Science, 81(5): 1025-1038.

Wade, N. 2014. A troublesome inheritance: Genes, race, and human history. New York: Penguin Press.

Winegard, B. et al. 2017. Human biological and psychological diversity. Evolutionary Psychological Science. doi:10.1007 /s40806-016-0081-5 